\title{
Interpersonal Continuity of Care and Care Outcomes: A Critical Review
}

\author{
Jobn W. Saultz, MD \\ Jennifer Locbner, MD \\ Department of Family Medicine, School \\ of Medicine, Oregon Health \& Science \\ University, Portland, Ore
}

\begin{abstract}
PURPOSE We wanted to undertake a critical review of the medical literature regarding the relationships between interpersonal continuity of care and the outcomes and cost of health care.

METHODS A search of the MEDLINE database from 1966 through April 2002 was conducted by the primary author to find original English language articles focusing on interpersonal continuity of patient care. The articles were then screened to select those articles focusing on the relationship between interpersonal continuity and the outcome or cost of care. These articles were systematically reviewed and analyzed by both authors for study method, measurement technique, and quality of evidence.
\end{abstract}

RESULTS Forty-one research articles reporting the results of 40 studies were identified that addressed the relationship between interpersonal continuity and care outcome. A total of 81 separate care outcomes were reported in these articles. Fifty-one outcomes were significantly improved and only 2 were significantly worse in association with interpersonal continuity. Twenty-two articles reported the results of 20 studies of the relationship between interpersonal continuity and cost. These studies reported significantly lower cost or utilization for 35 of 41 cost variables in association with interpersonal continuity.

CONCLUSIONS Although the available literature reflects persistent methodologic problems, it is likely that a significant association exists between interpersonal continuity and improved preventive care and reduced hospitalization. Future research in this area should address more specific and measurable outcomes and more direct costs and should seek to define and measure interpersonal continuity more explicitly.

Ann Fam Med 2005;3:159-166. DOI: 10.1370/afm.285

\section{INTRODUCTION}

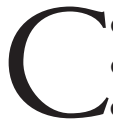

ontinuity of care traditionally is considered one of the core principles of family medicine, ${ }^{1,2}$ and it is a core element of the Institute of Medicine definition of primary care. ${ }^{3}$ Recently there has been a resurgence of interest in this subject, and the Annals of Family Medicine has devoted a theme issue to the topic. ${ }^{4}$ This resurgence has occurred in part because of the growing sophistication of research in family medicine and because of changes in American health care that many believe have undermined continuity in the relationship between physicians and their patients. ${ }^{5-11}$ A central question facing the future of family medicine is the degree to which we will provide personal health care based on the individual doctor-patient relationship, or whether we will seek to provide a medical home for patients based on an interdisciplinary team with less emphasis on personal care. ${ }^{12}$

Continuity has proved to be a difficult variable to define and measure. Several previous reviews of this subject have noted major limitations to its research foundation because of inconsistent definitions and complex methodologic challenges. ${ }^{13-18}$ In early 2002, we undertook a comprehensive review of the medical literature to examine one aspect of continuity 
of care related to the ongoing relationship between an individual doctor and patient. We defined this aspect of continuity as interpersonal continuity. This review has resulted in 2 publications, the first examining how interpersonal continuity of care has been defined and measured ${ }^{19}$ and the second evaluating the relationship between interpersonal continuity and patient satisfaction. ${ }^{20}$ For many family physicians and health care policy researchers, however, the most important questions about interpersonal continuity relate to the degree to which it is associated with improved outcomes or lower cost of health care. This article describes our review of the studies published in the medical literature before April 30, 2002, for evidence about these associations.

\section{METHODS}

A search of the MEDLINE database from January 1, 1966, to April 30, 2002, was conducted by the primary author using the medical subject heading "continuity of patient care," including all possible subheadings. Titles and reference citations of each of the resulting 2,424 citations in the English language were reviewed, and references were eliminated if they were letters to the editor, if they addressed health professions other than medicine, or if they clearly addressed only aspects of continuity other than interpersonal continuity. Excluding these citations left 379 references that appeared to address interpersonal continuity as an attribute of the relationship between clinicians and patients in general medical care. Full-text copies of each of these articles were obtained and read in detail by the primary author. In addition, the bibliography of each article was scanned to identify potential references that were missed by the MEDLINE search. The process of article review and exclusion has been previously described. ${ }^{19}$

This process yielded 142 articles that directly related to the concept of interpersonal continuity. Forty-one were review articles or theory articles dealing with continuity of care in general. The remaining 101 were original research reports. All of the citations were entered into a bibliographic database. Each was then classified by study method and primary research question(s), and this information was recorded in the database for each article. Each article was also reviewed to determine how continuity was defined and measured, and that information was also included in each database entry. This classification process has been described previously. ${ }^{19}$

The 142 articles addressed 13 different research themes related to interpersonal continuity of care. ${ }^{19}$ Two themes were the relationship of interpersonal continuity to care outcome and cost. Forty-one of the 101 original research reports addressed the relationship between interpersonal continuity of care and care outcome. These 41 articles described the results of 40 separate studies on this topic. We defined an improved care outcome conceptually as a measurable result of care that would generally be considered a desirable outcome or indicator of quality from a patient's point of view and that, ideally, would relate directly to reduced patient mortality or morbidity. Many of the improved care outcomes reported in these articles, however, are actually intermediate variables, such as improved diabetes control or improved delivery of preventive services. Twenty-two articles describing 20 original research projects were found that examined the association between interpersonal continuity and the cost of care. We defined a reduced cost of care as a measurably lower cost of either providing or receiving health care and might include direct costs to the patient or third party payer, such as emergency department visits or laboratory test utilization. We also included studies examining the costs of providing care, such as missed office appointments, because such missed appointments would reduce office efficiency and increase the cost of delivering care to the community.

Both authors systematically analyzed these 2 groups of articles to assess the significance and strength of these relationships. The goals of our analyses were to determine the quality of this evidence and to assess the methods used by previous authors to examine the associations. We originally considered a meta-analysis of these data, but we found it to be impossible because of the substantial differences in study methods and the manner in which care outcomes and costs were examined. Thus, our analyses consisted of a systematic review of each group of articles to assess the study method, the results of each study, and quality of evidence reported in each article.

Quality of evidence was evaluated by determining the degree to which each article addressed 5 quality characteristics (Table 1 displays outcome studies and Table 2 displays cost studies). We chose these 5 quality characteristics for each analysis after reading the chosen articles and discussing the project with colleagues. Each study was reviewed independently by the 2 authors and assigned a score of 2, 1, or 0 for each quality characteristic according to whether the characteristic was met, partially met, or not met, respectively. This subjective assessment was based on the independent judgment of each author. The scores listed in Table 1 are the average of these 2 scores except in those cases where the scores differed by more than 1 point. Whenever any of the scores differed by more than 1 point (one score was 2 and the other 0 ), the article in question was reread by both authors and discussed to reach consensus.

In some cases, we found it challenging to assign a 
Table 1. Quality Analysis of Studies Examining Interpersonal Continuity and Care Outcome

\begin{tabular}{|c|c|c|c|c|c|c|}
\hline Study & $\begin{array}{l}\text { Interpersonal } \\
\text { Continuity } \\
\text { Defined and } \\
\text { Measured in } \\
\text { Credible Way }\end{array}$ & $\begin{array}{l}\text { Study Design } \\
\text { Appropriate to } \\
\text { Study Question }\end{array}$ & $\begin{array}{c}\text { Outcome } \\
\text { Studied } \\
\text { Applicable to } \\
\text { FP Practices }\end{array}$ & $\begin{array}{c}\text { Outcome } \\
\text { Measured in } \\
\text { Credible Way }\end{array}$ & $\begin{array}{c}\text { Findings } \\
\text { Generalizable } \\
\text { to Other } \\
\text { Settings }\end{array}$ & $\begin{array}{c}\text { Overall } \\
\text { Quality of } \\
\text { Evidence }\end{array}$ \\
\hline Charney et al, $1967^{21}$ & 2 & 1.5 & 2 & 1.5 & 2 & 9 \\
\hline Alpert et al, $1968^{22}$ & 0 & 2 & 2 & 2 & 1.5 & 7.5 \\
\hline Alpert et al, $1970^{23}$ & 0 & 2 & 1.5 & 0.5 & 1 & 5 \\
\hline $\begin{array}{l}\text { Gordis \& Markowitz, } \\
1971^{24}\end{array}$ & 0.5 & 2 & 2 & 1.5 & 1 & 7 \\
\hline Gordis, $1973^{25}$ & 0 & 1.5 & 1 & 1 & 1 & 4.5 \\
\hline Becker et al, $1974^{26,27}$ & 0.5 & 2 & 1 & $1^{*}$ & 1.5 & 6 \\
\hline Starfield et al,1976 28 & 1 & 0.5 & 1 & 0 & 0.5 & 3 \\
\hline Alpert et al,1976 29 & 0 & 2 & 2 & 1 & 1.5 & 6.5 \\
\hline Roos et al, $1980^{30}$ & 2 & 0.5 & 1 & 0.5 & 0 & 4 \\
\hline Ettlinger \& Freeman, $1981^{31}$ & 1.5 & 1.5 & 2 & 1.5 & 2 & 8.5 \\
\hline Shear et al, $1983^{32}$ & 1.5 & $0 *$ & 2 & $1^{*}$ & 0.5 & 5 \\
\hline Wasson et al, $1984^{33}$ & 2 & 2 & 2 & 2 & 1 & 9 \\
\hline Phillips \& Shear, $1984^{34}$ & $1^{*}$ & 1 & 2 & 1.5 & 1 & 6.5 \\
\hline Flynn, $1985^{35}$ & 2 & 1 & 2 & 1 & 0.5 & 6.5 \\
\hline Susman et al, $1989^{36}$ & 1 & 1.5 & 2 & 1.5 & $1^{*}$ & 7 \\
\hline Hjortdahl, $1992^{37}$ & 2 & 1 & 1.5 & $1^{*}$ & 1 & 6.5 \\
\hline $\begin{array}{l}\text { Freeman \& Richards, } \\
1994^{38}\end{array}$ & 2 & 0.5 & 1 & 0 & 1 & 4.5 \\
\hline Petersen et al, $1994^{39}$ & $1^{*}$ & 1 & 1 & 1 & 0.5 & 4.5 \\
\hline Rowley et al, $1995^{40}$ & 0 & $1^{*}$ & 1.5 & 1.5 & 0 & 4 \\
\hline Smith, $1995^{41}$ & 0 & 1 & 1 & 1 & 0 & 3 \\
\hline Sweeney \& Gray, $1995^{42}$ & 1.5 & 0.5 & 2 & 0.5 & $2^{*}$ & 6.5 \\
\hline Ettner, $1996^{43}$ & 0.5 & 1.5 & 2 & 2 & 1 & 7 \\
\hline Lambrew et al, $1996^{44}$ & 1.5 & 1.5 & 2 & 1.5 & 2 & 8.5 \\
\hline Weiss \& Bluestein, 199645 & 2 & 2 & 2 & 1.5 & 2 & 9.5 \\
\hline Flocke et al, $199^{76}$ & 1.5 & 1 & 2 & 1.5 & 2 & 8 \\
\hline O'Malley et al, $1997^{46}$ & 1 & 1.5 & 2 & 2 & 1.5 & 8 \\
\hline Gill \& Mainous, $1998^{47}$ & 1.5 & 2 & 2 & 2 & 1 & 8.5 \\
\hline Mainous \& Gill, $1998^{48}$ & 2 & 2 & 2 & 2 & 1 & 9 \\
\hline O'Connor et al, $1998^{49}$ & 1 & 2 & 2 & 2 & 1.5 & 8.5 \\
\hline Ettner, $1999^{50}$ & 1 & 1.5 & 2 & 1.5 & 1 & 7 \\
\hline Howie et al, $1999^{51}$ & 1 & 1 & 1 & 0.5 & 1 & 4.5 \\
\hline Christakis et al, $2000^{52}$ & 2 & 2 & 2 & 1.5 & 1.5 & 9 \\
\hline Christakis et al, $2001^{53}$ & 2 & 2 & 2 & 2 & 1 & 9 \\
\hline Boss \& Timbrook，200154 & 2 & $2^{*}$ & 2 & 2 & 1 * & 9 \\
\hline Gallagher et al, $2001^{55}$ & 0.5 & 1 & 1.5 & 1.5 & 1 & 5.5 \\
\hline Hanninen et al, $2001^{56}$ & 1 & 2 & 2 & 2 & 1.5 & 8.5 \\
\hline Mainous et al, $2001^{57}$ & 2 & 1 & 1.5 & 1.5 & 1.5 & 7.5 \\
\hline Overland et al, $2001^{58}$ & 2 & 1.5 & 2 & 2 & 1 & 8.5 \\
\hline $\begin{array}{l}\text { Sturmberg \& Schattner, } \\
2001^{59}\end{array}$ & 2 & 2 & 1.5 & 1.5 & 1.5 & 8.5 \\
\hline Gill et al, $2002^{60}$ & 1 & 2 & 2 & 2 & 1.5 & 8.5 \\
\hline
\end{tabular}

particular outcome as either quality or cost (ie, either Table 1 or 2). For example, hospitalization rate can be considered to both an important driver of cost and an indirect indicator of care quality. We therefore decided to include studies examining hospitalization rate in both analyses. In contrast, we considered appointment no-show rates, emergency department visits, and office visit frequency to be costs, but not quality outcomes. 


\begin{tabular}{|c|c|c|c|c|c|c|}
\hline Study & $\begin{array}{l}\text { Interpersonal } \\
\text { Continuity Defined } \\
\text { and Measured in } \\
\text { Credible Way }\end{array}$ & $\begin{array}{l}\text { Study Design } \\
\text { Appropriate to } \\
\text { Study Question }\end{array}$ & $\begin{array}{c}\text { Cost Outcome } \\
\text { Measured } \\
\text { Applicable } \\
\text { to FP Practice }\end{array}$ & $\begin{array}{c}\text { Cost } \\
\text { Measured in } \\
\text { Appropriate } \\
\text { Manner }\end{array}$ & $\begin{array}{l}\text { Outcome } \\
\text { Studied } \\
\text { Applicable to } \\
\text { FP Practices }\end{array}$ & $\begin{array}{l}\text { Overall } \\
\text { Quality of } \\
\text { Evidence }\end{array}$ \\
\hline Alpert, $1964^{61}$ & 0.5 & 1 & 2 & 1.5 & 1.5 & 6.5 \\
\hline $\begin{array}{l}\text { Alpert et al, } \\
1968^{22} \& 1976^{29}\end{array}$ & 0 & 1.5 & 2 & 2 & 1.5 & 7 \\
\hline $\begin{array}{l}\text { Heagarty et al, } \\
1970^{62}\end{array}$ & 0 & 1.5 & 2 & 2 & 1.5 & 7 \\
\hline $\begin{array}{l}\text { Becker et al, } \\
1974^{26,27}\end{array}$ & 0.5 & 2 & 1.5 & 0.5 & 1 & 5.5 \\
\hline $\begin{array}{l}\text { Hennelly \& } \\
\text { Boxerman, } \\
1979^{63}\end{array}$ & $1^{*}$ & 0.5 & 1.5 & 1.5 & $1 *$ & 5.5 \\
\hline $\begin{array}{l}\text { Phillips \& Shear, } \\
1984^{34}\end{array}$ & $1^{*}$ & 1 & 1 & 0.5 & 0.5 & 4 \\
\hline Wasson et al, $1984^{33}$ & 2 & 2 & 2 & 2 & 1 & 9 \\
\hline $\begin{array}{l}\text { Hjortdahl \& } \\
\text { Borchgrevink, } \\
1991^{64}\end{array}$ & 0.5 & 1 & 1.5 & 1 & 1 & 5 \\
\hline Smith, $1995^{41}$ & 0.5 & 0 & 1.5 & 0.5 & 0 & 2.5 \\
\hline $\begin{array}{l}\text { Sweeney \& Gray, } \\
1995^{42}\end{array}$ & 1.5 & 0.5 & 2 & 1 & 2 & 7 \\
\hline Rowley et al, $1995^{40}$ & 0 & $1^{*}$ & 1 & 1 & 0.5 & 3.5 \\
\hline $\begin{array}{l}\text { Weiss \& Bluestein, } \\
1996^{45}\end{array}$ & 2 & 2 & 1.5 & 2 & 2 & 9.5 \\
\hline Cornelius, $1997^{65}$ & 1.5 & 2 & 2 & 2 & 1.5 & 9 \\
\hline $\begin{array}{l}\text { Gill \& Mainous, } \\
1998^{47}\end{array}$ & 1.5 & 1.5 & 2 & 1.5 & 1 & 7.5 \\
\hline $\begin{array}{l}\text { Mainous \& Gill, } \\
1998^{48}\end{array}$ & 2 & 1.5 & 2 & 1.5 & 1 & 8 \\
\hline Raddish et al, $1999^{66}$ & 1 & 1 & 2 & 1.5 & 1.5 & 7 \\
\hline $\begin{array}{c}\text { Christakis et al, } \\
1999^{67}\end{array}$ & 2 & 2 & 2 & 1.5 & 1.5 & 9 \\
\hline Gill et al, $2000^{68}$ & 2 & 1.5 & 2 & 2 & 1 & 8.5 \\
\hline $\begin{array}{l}\text { Meredith et al, } \\
2001^{69}\end{array}$ & 1.5 & 1.5 & 1 & 0.5 & 0.5 & 5 \\
\hline $\begin{array}{l}\text { Christakis et al, } \\
2001^{53}\end{array}$ & 2 & 2 & 2 & 2 & 1.5 & 9.5 \\
\hline \multicolumn{7}{|c|}{ Note: Scores are the average of independent reviews by 2 authors. } \\
\hline \multicolumn{7}{|c|}{$\mathrm{FP}=$ family physician; $2=$ yes $; 1=$ somewhat $; 0=$ no. } \\
\hline
\end{tabular}

\section{RESULTS}

Table 1 displays the 40 studies ( 41 articles) addressing the association between interpersonal continuity and care outcome, as well as our assessment of the quality of evidence in each study. Because each outcome was evaluated by the 5 criteria listed as column headings in Table 1, a total of 200 quality scores were assigned for the 40 studies. Independent review by the 2 authors resulted in scores that were similar. In 11 of the 200 cells, our quality score differed by more than 1 point. For each study, the sum of the scores for each criterion is listed in the last column of this table as a measure of overall study quality.

Table 2 displays the results of a similar analysis of the 20 studies (22 articles) addressing the association between interpersonal continuity and the cost of care. A total of 100 quality scores were assigned for these 20 studies. Our scores differed by more than 1 point in only 4 of the 100 . The scores listed in Table 2 are derived by using the same process described above. Table 2 also lists a total score ranking the quality of each of article in the last column.

In Supplemental Table 1 (http://www.annfammed. org/cgi/content/full/3/2/159/DC1 )we summarize each study by examining improved outcome and indicating whether a significant association existed between interpersonal continuity and each outcome being studied.

Many of the articles reported multiple outcomes. Supplemental Table 1 displays each reported outcome 
separately in the fourth column. The fifth column lists whether a significant association was found between interpersonal continuity and each outcome. Further details about the findings for each study are listed in the sixth column, and the quality score for each study (from Table 1) is listed in the last column. The studies in Supplemental Table 1 are displayed in order of decreasing total quality score.

In 5 of the 40 studies, the researchers failed to find a significant association between an improved outcome and interpersonal continuity. ${ }^{30,35,36,55,58}$ In 2 studies at least 1 care outcome was found that was significantly worse with interpersonal continuity. ${ }^{55,56}$ Twelve studies had a positive association for at least 1 outcome, but there was no significant association for other outcomes. ${ }^{*}$ The remaining 23 articles reported a positive association for all outcomes addressed in the study.

The most common outcomes examined in these studies were the delivery of preventive care (12 studies examined 22 separate outcome variables), ${ }^{\dagger}$ hospitalization rate ( 9 studies, 11 outcome variables), ${ }^{\ddagger}$ quality of doctor-patient relationship ( 5 studies, 5 outcome variables), ${ }^{26,38,42,51,57}$ chronic illness management indicators ( 4 studies, 8 outcome variables), ${ }^{34,49,56,58}$ and maternity care outcomes ( 4 studies, 16 outcome variables). ${ }^{32,35,40,54}$ Supplemental Table 2 (http://www.annfammed.org/cgi/

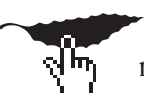

content/full/3/2/159/DC1) displays the most commonly studied care outcomes and is sorted by outcome category to allow comparison of results across multiple studies.

A total of 81 separate care outcomes were reported in these 41 articles. Of these outcomes, 51 were significantly improved in association with interpersonal continuity of care. In 2 cases, interpersonal continuity was found to be associated with a significantly worse outcome. Roos et $\mathrm{al}^{30}$ found that appropriate referral criteria for tonsillectomy were less likely to be documented when interpersonal continuity was present, and Gallagher et $\mathrm{al}^{15}$ found that women were more likely to receive counseling about hormone replacement therapy when they received care from both a family physician or internist and an obstetrician. No significant association or a mixed association was found in the remaining 28 outcomes.

There were 7 clinical trials, 14 cohort studies, 17 correlational studies, and 2 case control studies included in this analysis. Interpersonal continuity of care was measured in 10 different ways by these articles. These measurement methods have been previously reviewed..$^{19}$ The most common methods used were patient survey (10 studies),, usual provider continuity index (UPC, 6 studies), 6,38,41,48,54,57 index provider identification ( 5 studies), ${ }^{21,28,36,39,42}$ continuity of care index
(COC, 5 studies), ${ }^{30,33,35,52,53}$ and duration of relationship with the primary physician ( 5 studies). ${ }^{21,37,45,57,58}$ In 7 of the studies, including 6 of the 7 clinical trials, patients were assigned either to a clinic designed to deliver clinician continuity or to a clinic with no physician continuity. $22-26,29,40,70$ Unfortunately, the quality of evidence in these studies is compromised, because in only 1 study was continuity actually measured in either study group. ${ }^{33}$

Supplemental Table 3 (http://www.annfammed.org/ cgi/content/full/3/2/159/DC1) summarizes the 20 studies examining the association between interpersonal continuity and the cost of health care.

Only 1 of these studies directly examined the total cost of health care, ${ }^{65}$ and 1 study measured total Medicare part A and B costs. ${ }^{45}$ The most commonly examined cost variables were hospitalization rate (10 studies), " frequency of office visits (4 studies), ${ }^{29,34,63,66}$ emergency department visits (4 studies), 42,53,67,68 office appointment no-show rate (4 studies), ${ }^{26,29,42,61}$ and utilization of diagnostic tests (4 studies). ${ }^{29,33,62,64}$

Our review identified 5 clinical trials, 3 correlation studies, 2 case control studies, and 10 cohort studies (Supplemental Table 2). Eight different methods of measuring continuity of care were used in these 20 studies, and no method was used by more than 3 studies. In 3 of the 4 clinical trials, patients were assigned to clinics with or without continuity, but continuity was not measured in either study group. ${ }^{24,26,29,40,70}$ Only 1 study found no significant association between interpersonal continuity and any of the cost outcomes being studied. ${ }^{34}$ One study identified 2 cost outcomes that were significantly higher when interpersonal continuity was present. Hjortdahl and Borchgrevink ${ }^{64}$ found that increased interpersonal continuity was associated with increased prescription drug use and specialty referral. Nineteen of the 20 studies identified a significant association between interpersonal continuity and at least 1 reduced cost variable.

These studies examined a total of 41 cost variables. A significant positive association was found between reduced cost and interpersonal continuity for 35 of these variables. Two cost outcomes were higher, and no significant association was found for the remaining 4. One of the cohort studies examined interpersonal continuity as the dependent variable in a managed care environment and found a significant association between more restrictive utilization and increased continuity of care. ${ }^{69}$

\footnotetext{
* References 21, 22, 24, 26, 32, 38, 40, 43, 45, 49, 50, 56.

† References 22, 24, 26, 29, 43-46, 50, 52, 55, 60 .

† References 22, 29, 32, 33, 41, 45, 47, 48, 53.

$\S$ References $31,43,44,46,49-51,55,56,60$

|| References 29, 33, 34, 39-41, 45, 47, 48, 53, 66 .
} 


\section{DISCUSSION}

Our literature search identified 9 review articles published before April 30, 2002, that examined the evidence of an association between interpersonal continuity and improved outcomes or lowered cost. ${ }^{13-15,71-76}$ Most previous reviews of interpersonal continuity have reported an association between such continuity and patient satisfaction, ${ }^{20}$ but evidence of improved outcome or reduced cost has been deemed less conclusive. All these reviews cite persistent methodologic challenges regarding the definition and measurement of continuity of care, and most concluded that there was insufficient evidence that such continuity uniformly improves care. ${ }^{14,15,71-75}$ One author raised the possibility that transient discontinuity might actually improve care by allowing new insights into the process of diagnosis and management. ${ }^{75}$ Since we began our review, several additional studies that examined the association of continuity of care and improved outcomes have been published in the primary care literature. ${ }^{70,77-83}$ We chose not to include these articles in our review, because we have not systematically searched the literature for all studies published after April 2002.

Our results suggest that interpersonal continuity is associated with improvement in some outcomes of care. In particular, interpersonal continuity seems to be associated with improved delivery of preventive services and with lower rates of hospitalization. An association between interpersonal continuity and improved measures of chronic illness care is less clear from our review. It is also important to remember that association does not imply causation. Most of the studies included in this review are retrospective cohort studies or cross-sectional patient surveys, which do not allow us to evaluate a cause-effect relationship. Seven studies included in our analysis were clinical trials, a method that would allow us to evaluate causation, but 6 of them did not report a measurement of interpersonal continuity in either study group. So although patient assignment may have been randomized, the degree to which continuity was superior in the intervention groups is unclear. Other differences between the control and intervention groups in these trials also confounded the results. In the only clinical trial that did show better continuity in the intervention group, Wasson et $\mathrm{al}^{33}$ found significantly fewer hospitalizations, fewer intensive care unit days, and shorter hospital lengths of stay in elderly male veterans.

Even though a cause-effect relationship between interpersonal continuity and reduced hospitalization and improved preventive health measures is possible, it is important to entertain other possibilities as well. It could be that increased interpersonal continuity is the effect of patients experiencing desired health outcomes rather than the cause of these outcomes (ie, patients with good outcomes are happier with their care and choose to maintain longer term relationships with their clinicians than are patients with poorer health outcomes). Perhaps the long-term doctor-patient relationship is representative of some other characteristic of the patient that is, in fact, more directly related to improved outcomes, or perhaps it is representative of a well-coordinated system of care, which as a whole contributes to improved patient health outcomes.

Similar to previous reviews, we found considerable diversity in how interpersonal continuity was measured and widely different techniques of measuring care outcomes. Two studies suggested that outcomes might be improved when a larger number of physicians were involved in the care (reduced interpersonal continuity). ${ }^{30,55}$ In only 1 study was interpersonal continuity associated with increased cost. ${ }^{64}$ None of the other studies included in this review associated interpersonal continuity with worse outcome or higher cost. In fact, 35 of 40 studies found a positive association with at least 1 improved outcome of care, and 51 of the 81 outcomes examined in these studies were significantly improved.

Nineteen of 20 studies associated interpersonal continuity with lower cost and 35 of 41 cost variables were significantly lower. Unfortunately, all but 1 of the cost studies examined only an indirect aspect of cost, and only 1 actually correlated total health care cost with continuity of care..$^{65}$ The highest quality studies uniformly found an association between interpersonal continuity and lower cost variables, but again no inference can be made about cause-effect relationships because of the limitations of study methods.

In conclusion, the available medical literature suggests that interpersonal continuity of care is associated with significant improvement in at least some care outcomes. The strongest evidence of such an association is for those outcomes that have been most frequently studied: preventive services and hospitalization. There are fewer studies addressing the association between continuity and cost, and most have looked at only 1 or 2 indirect aspects of cost. Continuity research continues to be limited by inconsistencies in how continuity is defined and measured, but recent work seems to be creating more consensus on these issues. Christakis ${ }^{84}$ has suggested that, "it is time to declare continuity of care an outcome and to spur subsequent research in how to better achieve it." If we consider continuity of care an outcome, however, are we really sure that it is a desirable outcome? Those of us in primary care would likely answer yes, but the behavior of health plans and health system planners suggests that others might not be convinced. The discipline of family medi- 
cine has always been predicated on a core assumption that interpersonal continuity of care is as important to patients as it is to family physicians. Now that our research expertise is maturing, it is time to prove that this assumption is valid.

To read or post commentaries in response to this article, see it online at http://www.annfammed.org/cgi/content/full/3/2/159.

Key words: Continuity of patient care; primary health care; physicianpatient relations; quality of health care; health care costs

Submitted February 17, 2004; submitted, revised, June 7, 2004; accepted July 27, 2004.

\section{References}

1. Saultz JW. Continuity of care. In: Saultz JW, ed. Textbook of Family Medicine. 1st ed. New York, NY: McGraw-Hill; 2000:52-77.

2. McWhinney IR. Principles of family medicine. In: McWhinney IR, ed. A Textbook of Family Medicine. 2nd ed. New York, NY: Oxford University Press; 1997:18-20.

3. Committee on the future of primary care. Primary Care: America's Health in a New Era. 1st ed. Washington, DC: Institute of Medicine: National Academy of Sciences; 1996.

4. Stange KC. In this issue: continuity of care. Ann Fam Med. 2003;1:130-131.

5. Emanuel EJ, Dubler NN. Preserving the physician-patient relationship in the era of managed care. JAMA. 1995;273:323-329.

6. Flocke SA, Stange KC, Zyzanski SJ. The impact of insurance type and forced discontinuity on the delivery of primary care. J Fam Pract. 1997;45:129-135.

7. Kikano GE, Flocke SA, Gotler RS, Stange KC. 'My insurance changed': the negative effects of forced discontinuity of care. Fam Pract Manage. 2000;7:44-45.

8. Bagley B. Hospitals and the family physician. Am Fam Phys. 1998;58:336-339.

9. Fleming DM. Continuity of care: a concept revisited. Eur J Gen Pract. 2000;6:140-145.

10. Kahana E, Stange KC, Meehan R, Raff L. Forced disruption in continuity of primary care: the patients' perspective. Sociol Focus. 1997;30:177-187.

11. Kogan MD, Alexander GR, Teitelbaum MA, Jack BW, Kotelchuck M, Pappas G. The effect of gaps in health insurance on continuity of a regular source of care among pre-school aged children in the United States. JAMA. 1995;274:1429-1435.

12. Future of Family Medicine Project Leadership Committee. The future of family medicine: a collaborative project of the family medicine community. Ann Fam Med. 2004;2(Suppl 1):S3-S32. Available at: http://www futurefammed.org.

13. Dietrich AJ, Marton KI. Does continuous care from a physician make a difference? J Fam Pract. 1982;15:929-937.

14. Freeman G. Continuity of care in general practice: a review and critique. Fam Pract. 1984;4:1192-1194.

15. Wall EM. Continuity of care and family medicine: definition, determinants, and relationship to outcome. J Fam Pract. 1981; 13:655-664.

16. Starfield B. Continuous confusion? Am J Public Health. 1980;70:117119.

17. Baker R. Will the future GP remain a personal doctor? Br J Gen Pract. 1997;47:831-34.
18. Rogers J, Curtis P. The concept and measurement of continuity in primary care. BMJ. 1980;70:122-127.

19. Saultz JW. Defining and measuring interpersonal continuity of care Ann Fam Med. 2003;1:134-143.

20. Saultz JW, Albedaiwi W. Interpersonal continuity of care and patient satisfaction: a critical review. Ann Fam Med. 2004; 2:445-451.

21. Charney E, Bynum R, Eldredge D, et al. How well do patients take oral penicillin? A collaborative study in private practice. Pediatrics. 1967;40:188-195.

22. Alpert JJ, Heagarty MC, Robertson L, Kosa J, Haggerty RJ. Effective use of comprehensive pediatric care. Amer J Dis Child. 1968;116:529-533.

23. Alpert JJ, Kosa J, Haggerty RJ, Robertson LS, Heagarty MC. Attitude and satisfactions of low-income families receiving comprehensive pediatric care. Am J Public Health. 1970;60:499-506.

24. Gordis L, Markowitz M. Evaluation of the effectiveness of comprehensive and continuous pediatric care. Pediatrics. 1971;48:766-776.

25. Gordis L. Effectiveness of comprehensive-care programs in preventing rheumatic fever. N Engl J Med. 1973;289:331-335.

26. Becker $\mathrm{MH}$, Drachman RH, Kirscht JP. A field experiment to evaluate various outcomes of continuity of physician care. Am J Public Health. 1974;64:1062-1070.

27. Becker $\mathrm{MH}$, Drachman RH, Kirscht JP. Continuity of pediatrician: new support for an old shibboleth. J Pediatr. 1974;84:599-605.

28. Starfield BH, Simborg DW, Horn SD, Yourtee SA. Continuity and coordination in primary care: their achievement and utility. Med Care. $1976 ; 14: 625-636$.

29. Alpert JJ, Robertson LS, Kosa J, Haggerty MC, Haggerty RJ. Delivery of health care for children: report of an experiment. Pediatrics. 1976;57:917-930.

30. Roos LL, Roos NP, Gilbert P, Nicol JP. Continuity of care: does it contribute to quality of care? Med Care. 1980;18:174-184.

31. Ettlinger PR, Freeman GK. General practice compliance study: Is it worth being a personal doctor? BMJ. 1981;282:1192-1194.

32. Shear CL, Gipe BT, Mattheis JK, Levy MR. Provider continuity and quality of medical care. Med Care. 1983;21:1204-1210.

33. Wasson JH, Sauvigne AE, Mogielnicki RP, et al. Continuity of outpatient medical care in elderly men: a randomized trial. JAMA. 1984;252:2413-2417.

34. Phillips DM, Shear CL. Provider continuity and control of hypertension. J Fam Pract. 1984;19:793-797.

35. Flynn SP. Continuity of care during pregnancy: the effect of provider continuity on outcome. J Fam Pract. 1985;21:375-380.

36. Susman J, Zervanos NJ, Byerly B. Continuity of care and outcome in nursing home patients transferred to a community hospital. Fam Med. 1989;21:118-121

37. Hjortdahl P. Continuity of care: general practitioners' knowledge about, and sense of responsibility toward their patients. Fam Pract. 1992;9:3-8.

38. Freeman GK, Richards SC. Personal continuity and the care of patients with epilepsy in general practice. Br J Gen Pract. 1994;44:395-399.

39. Petersen LA, Brennan TA, O'Neil AC, Cook EF, Lee TH. Does housestaff discontinuity of care increase the risk for preventable adverse events? Ann Intern Med. 1994;121:866-872.

40. Rowley MJ, Hensley MJ, Brinsmead MW, Wlodarczyk JH. Continuity of care by a midwife team versus routine care during pregnancy and birth: a randomized trial. Med J Aust. 1995;163:289-293.

41. Smith CS. The impact of an ambulatory firm system on quality and continuity of care. Med Care. 1995;33:221-226.

42. Sweeney KG, Gray DP. Patients who do not receive continuity of care from their general practitioners-are they a vulnerable group? Br J Gen Pract. 1995;45:133-135. 
43. Ettner SL. The timing of preventive services for women and children: the effect of having a usual source of care. Am J Public Health. 1996;86:1748-1754.

44. Lambrew JM, DeFriese GH, Carey TS, Ricketts TC, Biddle AK. The effects of having a regular doctor on access to primary care. Med Care. 1996;34:138-151

45. Weiss LJ, Bluestein J. Faithful patients: the effect of longterm physician-patient relationships on the cost and use of health care by older Americans. Am J Public Health. 1996;86:1742-1747.

46. O'Malley AS, Mandelblatt J, Gold K, Cagney KA, Kerner J. Continuity of care and the use of breast and cervical cancer screening services in a multiethnic community. Arch Intern Med. 1997;157:1462-1470.

47. Gill JM, Mainous III AG. The role of provider continuity in preventing hospitalizations. Arch Fam Med. 1998;7:352-357.

48. Mainous III AG, Gill JM. The importance of continuity of care in the likelihood of future hospitalizations: is site of care equal to a predominant clinician? Am J Public Health. 1998;88:1539-1541.

49. O'Connor PJ, Desai J, Rush WA, Cherney LM, Solberg LI, Bishop DB. Is having a regular provider of diabetes care related to intensity of care and glycemic control? J Fam Pract. 1998;47:290-297.

50. Ettner SL. The relationship between continuity of care and the health behavior of patients. Med Care. 1999;37:547-555.

51. Howie JG, Hearney DJ, Maxwell M, Walker JJ, Freeman GK, Rai H. Quality at general practice consultations: cross sectional survey. BMJ. 1999:319:738-743.

52. Christakis DA, Mell L, Wright JA, Davis R, Connell FA. The association between greater continuity of care and timely measles-mumpsrubella vaccine. Am J Public Health. 2000;90:962-965.

53. Christakis DA, Mell L, Koepsell TD, Zimmerman J, Connell FA. Association of lower continuity of care with greater risk of emergency department use and hospitalization in children. Pediatrics. 2001;103:524-529.

54. Boss DJ, Timbrook RE. Clinical obstetric outcomes related to continuity in prenatal care. JABFP. 2001;14:418-423.

55. Gallagher TC, Geling O, Comite F. Use of multiple providers for regular care and women's receipt of hormone replacement therapy counseling. Med Care. 2001;39:1086-1096.

56. Hanninen J, Takala J, Keinanen-Kiukaanniemi S. Good continuity of care may improve quality of life in Type 2 diabetes. Diabetes Res Clin Pract. 2001:51:21-27.

57. Mainous III AG, Baker R, Love MM, Pereira Gray DJ, Gill JM Continuity of care and trust in one's physician: evidence from primary care in the United States and the United Kingdom. Fam Med. 2001;33:22-27.

58. Overland J, Yue DK, Mira M. Continuity of care in diabetes: to whom does it matter? Diabetes Res Clin Pract. 2001;52:55-61.

59. Sturmberg JP, Schattner P. Personal doctoring. Its impact on continuity of care as measured by the comprehensiveness of care score. Aust Fam Phys. 2001;30:513-518.

60. Gill JM, Saldarriaga A, Mainous III AG, Unger D. Does continuity between prenatal and well-child care improve childhood immunizations? Fam Med. 2002;34:274-280.

61. Alpert JJ. Broken appointments. Pediatrics. 1964;34:132.

62. Heagarty MC, Robertson LS, Kosa J, Alpert JJ. Some comparative costs in comprehensive versus fragmented pediatric care. Pediatrics. 1970;46:596-603.
63. Hennelly V, Boxerman S. Continuity of medical care: its impact on physician utilization. Med Care. 1979;17:1012-1018.

64. Hjortdahl P, Borchgrevink C. Continuity of care: influence of general practitioners' knowledge about their patients on use of resources in consultations. BMJ. 1991;303:1181-1184.

65. Cornelius LJ. The degree of usual provider continuity for African and Latino Americans. J Health Care Poor Underserved. 1997;8:170-185.

66. Raddish M, Horn SD, Sharkey PD. Continuity of care: is it cost effective? Am J Managed Care. 1999;5:727-734

67. Christakis DA, Wright JA, Koepsell TD, Emerson S, Connell FA. Is greater continuity of care associated with less emergency department utilization? Pediatrics. 1999;103:738-742.

68. Gill JM, Mainous III AG, Nsereko M. The effect of continuity of care on emergency department use. Arch Fam Med. 2000;9:333-338.

69. Meredith LS, Sturm R, Camp P, Wells KB. Effects of cost-containment strategies within managed care on continuity of the relationship between patients with depression and their primary care providers. Med Care. 2001;39:1075-1085.

70. Parchman ML, Burge SK. The physician-patient relationship, primary care attributes and preventive services. Fam Med. 2004;36:22-27.

71. Hansen MF. Continuity of care in family practice. J Fam Pract. 1975:2:439-444.

72. Leopold N, Cooper J, Clancy C. Sustained partnership in primary care. J Fam Pract. 1996;42:129-137.

73. Lewis C. Does comprehensive care make a difference? What is the evidence? Amer J Dis Child. 1971;122:469-474.

74. Guthrie B, Wyke S. Does continuity in general practice really matter? BMJ. 2000;321:734-736.

75. Tandeter HB, Vinson DC. Transient discontinuity of care: others seeing what we have missed. J Fam Pract. 1998;47:423-424.

76. Weyrauch KF. The personal knowledge of family physicians for their patients. Fam Med. 1994;26:452-455.

77. Parchman ML, Burge SK., Residency Research Network of South Texas Investigators. Continuity and quality of care in type 2 diabetes: a Residency Research Network of South Texas study. J Fam Pract. 2002;51:619-624.

78. Parchman ML, Pugh JA, Noel PH, Larme AC. Continuity of care, selfmanagement behaviors, and glucose control in patients with type 2 diabetes. Med Care. 2002;40:137-144.

79. Xu KT. Usual source of care in preventive service use: a regular doctor versus a regular site. Health Serv Res. 2002;37:1509-1529.

80. Gill JM, Mainous A, III, Diamond JJ, Lenbard MJ. Impact of provider continuity on quality of care for persons with diabetes mellitus. Ann Fam Med. 2003;1:162-170.

81. Parkerton PH, Smith DG, Straley HL. Primary care practice coordination versus physician continuity. Fam Med. 2004;36:15-21.

82. Mainous III AG, Kern D, Hainer B, Kneuper-Hall R, Stephens J, Geesey ME. The relationship between continuity of care and trust with stage of cancer at diagnosis. Fam Med. 2004;36:35-39.

83. De Maeseneer JM, De Prins L, Gosset C, Heyerick J. Provider continuity in family medicine: does it make a difference for total health care costs. Ann Fam Med. 2004;1:144-148.

84. Christakis DA. Continuity of care: process or outcome? Ann Fam Med. 2004; 1:131-133. 